\title{
Innovations in Multilingual Classroom: Exploring Teachers' Experiences
}

Guru Prasad Poudel

\begin{abstract}
This article explores the English language teachers' innovative practices on multilingual education and their experiences on using multilingual strategies in the classroom. In order to find out the teachers' innovative practices in multilingual education and their strategies for multilingual instruction, a semi structured interview and small group discussion was taken. The results of the study concluded that English language teachers involved their students in the use of multiple languages that they know for developing content knowledge. The teachers believed that multilingual approach supports the students to be linguistically and culturally resourceful. As a part of the experiences of the use of multilingual strategies, the study identified that the teachers linked up vocabulary meaning in different language; used translation as a technique to clarify the concept; provided exposure in multiple languages, facilitated the learners to be bilingual through language transfer; encouraged students to contribute something in their own language; allowed questions in students' own languages; and used as many languages as possible as the resource pool to impart information to the students.
\end{abstract}

Keywords: multilingualism, multilingual education, pedagogical practices, teachers' experiences

\section{Introduction}

No society is absolutely homogeneous. Heterogeneity, diversity and myriad linguistic affluence have become the characteristics of modern society. Our societies are linguistically rich and culturally diverse (Edwards, 2010). Education system of a nation has a big impact on preserving and promoting the languages spoken within the nation. The classroom instruction based on multilingual practices can give a justice to the students' languages irrespective of taking them as inferior or superior. Teachers' practice of using multiple languages in a classroom can be an asset to enhance broader understanding of worldview and socio-cultural issues. School is a miniature society (Deway, 1938) and classroom is a community of diverse students. Nepalese English language teaching classrooms are culturally and linguistically diversified. The students are from different ethnic and linguistic backgrounds. Getting such students in a classroom has become a matter of pride and prejudice. It is pride in the sense that teachers get an opportunity to learn and face multiple languages in a single class. On the other hand, they may have to face challenges to give equal justice to every indigenous language, as a result of which it can be a problematic situation.

English language teachers might have been facing the problem of managing diverse languages of the students in the classroom; however the existing studies have not well reflected those issues in advance (Splosky, 2012). Thus, there is a need of an intensive study on multilingual approaches and classroom based strategies. Multilingual pedagogical approaches are the means to expose learners with multiple languages in classroom discussion. Multilingual education refers to the act of providing knowledge of more than two languages to communicate with many people in both personal and professional contexts. Similarly, multilingual pedagogical approaches are the ways to capitalize diverse linguistic, cultural and 
literacy skills. Multilingual instructional strategies can promote identity investment among both majority and minority students in an educational program. Multilingual education encourages students to express themselves in their both first and second or target languages. Investing two or more languages within a classroom setting can be a powerful tool to develop language and literacy skills and increase metalinguistic awareness (Edwards, 2010).

In order to achieve multilingualism practices in education whether formal or informal, one needs to revisit the official language policy acts in a given country to help in strengthening multilingualism practices in the country concerned hence showing its significance in the fast growing world. The study of Okal (2014) has presented some measures to sustain multilingual education in English language teaching. He views that multidimensional communication skills should be used both in primary and secondary levels for the purposes of getting the learner access to both content and skills. Making dictionaries and publishing of grammar and story books in any language are the fastest ways of spurring language growth and preservation. Writing and staging drama and poetry in indigenous languages can help in the enhancement of multilingualism practices in education. There should also be official documents in mother tongue and or indigenous languages. The discussions upon the alternative means of teaching English could oil for the further practices of multilingual approaches in teaching English.

Throughout the work, this study explored the teachers' experiences on adopting multilingual approaches in classroom to raise awareness and to support students with the recourses from different languages that the students bring inside the classroom.

\section{Statement of the Problem}

As multilingualism has become an integral aspect of academia, language teachers face challenges in addressing the multiple learning needs of students from diverse linguistic and cultural backgrounds. It seems quite difficult to create multilingual classroom in the culturally and linguistically diversified classes because almost all the classes from primary to higher level in our public schools are heterogeneous in structure (Rai \& Phyak, 2011). Though people are in favor of multilingual strategies in classroom discussion, the selection and practices of multilingual instructional policies in the context of Nepal have not been made so far. In such a situation, discourse on the ways to make classroom really multilingual has become significant to discuss. Drawing on recent studies from second language studies, applied linguistics, literacy studies and English language teaching (Okal, 2014; Garcia \& Sylvan, 2011; \& Piller, 2016), a strong voice has been raised for exploring both global and local perspectives of multilingualism and diversity in language education. Equally, a recent surge in the use of multilingual pedagogical approaches is having an impact on how English and other languages are taught and learned (SSDP, 2016). While focusing on multilingual approaches to language education, a dire need has existed in exploring ways in which to capitalize on diverse linguistic, cultural and literacy skills through classroom pedagogical practices. In this regard, it seems relevant to discuss on the issue of the ways for making classroom multilingual. On the other hand, multilingual pedagogy can offer more opportunities and develop communicative capabilities in the learners (Koirala, 2016). Learners can be supported with the reading materials developed in different 
languages or simply they can be encouraged to respond on their language if they lack ideas to express in the target language. In this case, this work aimed at exploring the teachers' perceptions on the use of multiple languages in teaching English and their experiences of using various strategies to support the learners to be multilingual. it is the right time to think about the ways of making classroom multilingual.

\section{Review of Literature}

Multilingualism is referred to as the ability of a speaker to express himself or herself in several languages with equal and native like proficiency. Multilingualism can also be regarded as the coexistence of several languages within a society (Okal, 2014). These several languages can be official or unofficial, native or foreign and national or international. Multilingualism is seen as an umbrella term that covers a wide variety of linguistic contexts and practices including language status, speaker status, national histories, individual proficiencies and institutional contexts of language teaching and learning (Piller, 2016). Any given country or society is generally considered as a multilingual one if its members or citizens are multilingual. The multilingual citizens on many occasions tend to show identifiable full range of communicative competence in several languages in place.

In recent years the attempts have been made to include multiple languages in education as a resource to construct new forms of understanding to the students (Cenoz, 2013). Developing multilingual proficiency (Hardina \& Jesner, 2002) has become a focus of language education which includes the cumulative development of more language system in children's' learning skills and qualities.

\section{Roles of Multilingual Education}

Realizing the role of multilingualism, Cummins (2007) has presented that multilingual pedagogical approaches help in the: transfer of conceptual elements, transfer of meta-cognitive and meta-linguistic strategies, transfer of pragmatic aspects of language use, transfer of specific linguistic elements, and the transfer of phonological awareness.

In the same way, Hawkings (1984) has presented three important roles of multilingual approaches in education. They include: the knowledge of language (i.e., ability to use language appropriately in many situations; awareness of social and pragmatic norms; knowledge about language (i.e., forms and function of systems-grammar, phonology, vocabulary); and pedagogical practice (i.e., creating language learning opportunities; classroom interaction). Moreover, dealing with the role of multilingual education, Daniel, Orwego, Ruth and Nuding (2014) emphasize the three major significances as: engaging prior understanding, integrating factual knowledge with conceptual frameworks, and taking active control over the learning process through meta-cognitive strategies.

The knowledge of multiple languages is relevant to the issue of teaching for cross-linguistic transfer. In this regards, Duff (2015, p. 4) points out that new understandings are constructed on a foundation of existing understandings and experiences via multilingual education. Similarly, Manyak (2004) adds that multilingual repertoire can be a complement to produce the type of composite language competence that suits their needs. Garcia and Wei (2009) reported that the use of students' home languages is necessary in multilingual schools to support for their full participation in learning processes. Moreover, Cummins 
(2007) states that the knowledge of one language supports learning of another language and transferability of skills from one language to another language.

The language of instruction not only affects the child's acquisition of basic skills in education but can also help the child in successfully meeting the challenges in their lives. An appropriate language of instruction improves the child's opportunities for education, access and achievement. At present, there is a strong voice for using multiple languages as the languages of instruction. People have become more aware on the value of languages. Cenoz (2013) proposed three fundamental reasons behind people awareness on multilingual education as: i) the spread of English; ii) language policies to promote minority languages; iii) the mobility of the population, and multilingualism in school contexts for developing multi-competence (p. 14).

Although multilingualism is the norm in the world, the English-speaking world often dismisses the value of languages other than English (LOTEs). This is because of the status of English as a powerful world language - the language of empire, imperialism, and globalization (Garcia, 2011). Thus, speakers born to monolingual English-speaking parents often see themselves as superior to those who speak other languages, and self-sufficient in their monolingualism. The field of English language teaching has seldom paid any attention to the multilingualism (Pennycook, 2001) of students of English, often dismissing what students know or understand in languages other than English (Garcia, 2011).

Developing and training both foreign and indigenous language teachers are very instrumental steps to help in the achievement of multilingualism practices in education (Mutiga, 2005). There should also be an establishment of translation bodies with linguistic experts to help in the translation of both indigenous and foreign languages. When foreign and indigenous languages are included in the multilingualism practices in education, then we should always try to avoid imposing these languages to the people. A keen measure and clear framework should be taken into account because imposing languages to people is dangerous and may cause tensions amongst different ethnic and or speech communities (Rai \& Phyak, 2011).

\section{Effects of Multilingual Education}

Multilingualism practice creates the development of mixed languages mainly due to intense language contact. As a result speakers therefore tend to involve a mixture of languages during verbal communication (Daniel, Orwego, Ruth \& Nuding, 2014). Similarly, multilingual practice generally develops cross linguistic communication strategies like code switching and code mixing. Multilingualism creates an aspect of diglossia whereby when there are two official languages, there is always one language that tends to dominate the other which is generally referred to as subordinate (Philipson, 1997). In the same way, multilingualism practice tends to create the development and general acquisition of cross-cultural communication skills.

Some major benefits of multilingualism in education whether formal or informal include: the creation and appreciation of cultural awareness, adds academic and educational value, enhances creativity, adjustment in society and appreciation of local languages (Okal, 2014). Similarly, the knowledge of more than two languages allows us to communicate with many people in both personal and professional 
contexts. In the same way, entrenching multilingualism in education will of course enable one to avoid restrictions in communication thus enabling him to move to another stage of communication. On the other hand, multilingual educational practices enhance intellectual flexibility and creativity. In a sense, multilingualism also provides an insight into the understanding of different cultures and experiences hence a multilingual becomes multicultural in nature. It is also a form of human capital and social capital. In its specific sense, multilingualism helps in national unity especially if people learn national languages besides their indigenous languages and lingua franca (Gracia, 2014).

Nepal is a multilingual, multiethnic and multi cultural country. The classroom structure of students is also multilingual. Though the learners can be monolingual, the heterogeneous nature of English language classroom always invites the use of more than a language in instruction in the context of Nepal. The world practices has become more appealing to multilingual pedagogy (Garcia \& Kleifgen, 2010), however the government of Nepal has promoted monolingual practice along with the policy of English as a medium of instruction. In this regards, there is the space for the discussion on multilingual education and multilingual strategies for teaching English to the students in heterogeneous classroom.

\section{Methodology}

This is a qualitative study that draws on critical interpretation. Critical interpretative design focuses on raising the consciousness of the participants' values and beliefs that underpin their seemingly natural forms of opinions on the issue raised. The primary purpose behind the selection of critical interpretative paradigm is to identify, contest and demonstrate critical self-awareness and critical understanding of the complexity of issues through the in-depth analysis of participants' eye-views (Taylor and Medina, 2013). In qualitative research studies, the sample size depends on the scope of the study, the nature of the topic, the quality of the data, the study design, and the use of shadowed data (Morse, 2000, 2001). The participants of this study included five English language teachers who had an experience of teaching in multilingual classroom setting and the knowledge of multilingual pedagogical approaches. The researcher came to learn this through informal interaction and thus the participants were purposively selected.

The participants of the study comprised university level English teachers who had the experience of teaching English for more than ten years. They were the multilingual speakers with an ability to communicate in English, Nepali and Hindi. They were aware on multilingual approaches as they informed the researcher during informal interaction which was held while taking consent for the interview. They were well acquainted with the importance of multilingual approaches in teaching English to non native English speaking students and equally had the experiences of using multilingual strategies in their classroom practices.

A semi-structured interview and a focus group discussion were used as data collection tools. The objective of an interview is to capture the participants' language, including any references or appeals to other discourses (Starks \& Trinidad, 2007). Similarly, focus group discussion (FGD) was held among the ten teachers and two experts of multilingual education. Interpretive method of analysis was used so as to analyze the data. Interpretive analysis is an iterative, inductive process of de-contextualization and re- 
contextualization (Ayeres, Kavanaugh, \& Knafl, 2003; Morse \& Field, 1995 as cited in Starks \& Trinidad, 2007). During de-contextualization, the researcher separated data from the original context of individual cases and assigned codes to units of the texts. In re-contextualization, the researcher examined the codes for patterns and then reintegrated, organized and reduced the data around central themes and relationships drawn across all the cases and narratives. Similarly, the outcome of analysis is entirely based on the teachers' experiences on multilingual classroom practices and the alternatives to practice multilingual pedagogy in ESL/EFL classes. Thematic networking (i.e. an analytic tool) was used for the analysis and interpretation of the data from interview and FGD. It refers to deriving themes from textual data and interpreting with some representational tool (Strilling, 2001) with an aim to facilitate the structuring and depiction of the themes. The researcher established connection between explicit statements and the implicit meaning including claim, warrant and backing in the analysis and interpretation part.

\section{Results and Discussion}

The data collected via interview and FGD have been discussed in relation to the research questions and the results have been made as consistent as possible with the objectives of the study. The first part of the discussion relates to the teachers' innovative practices in multilingual classroom and the second part is on the experiences of using multilingual strategies in teaching English.

\section{Innovations in Making Classroom Multilingual}

Multilingualism and multilingual pedagogy are the recent areas of applied linguistics in relation to language, identity and transnationalism (Duff, 2015). These two domains are concerned with the issues pertaining to languages and literacy in the real world and with the people who learn, speak, write, process, translate, test, teach, use, and lose language in myriad ways. Teachers are taken as the change agents of the society and the critical educators (Cummins, 2007) to bring innovation in the education system of a nation. During the interview, I asked them to respond on the questions related to the innovative practices on multilingual pedagogy in relation to interrelated themes.

Almost all the teachers and participants of the FGD preferred that the pedagogy should be multilingual. They viewed that while teaching English as a second language in class, the focus should be on resources and the construction of new knowledge. The participants insisted that monolingual approach often creates a linguistic boundary and gives limited exposure to the students. In their experiences, diagnosing the needs of the students is the basic thing. Many of the students they taught expected examples, explanation and knowledge from multiple resources. The classroom structure they teach the students is multilingual and in such a situation how monolingual approach work well is their question. They also argued that the globalization, urbanization and migration have made a classroom linguistically mosaic. In such a situation, the use of only one language cannot provide social and linguistic capital to the learners. So, they reflected that if one really wants to enhance students' knowledge, he/she should expose students in their own languages but if one wants to teach only language not the content, then monolingual pedagogy would be appropriate. They strongly rejected the idea of monolingual pedagogy to enhance students' knowledge. For evidence, teacher-3 reported as: 
I think exposing students only in a language does not provide knowledge and resource to them. What I believe is knowledge is not constructed out of a language; it is constructed by the use of languages that we have or we bring in classroom. So,... for me pedagogy should be multilingual. I am trying my best for making classroom multilingual. Teachers' ease is a major thing to adopt multilingual pedagogy. We have to allow the resources of students' first language. For the beginners, multilingual instruction can be an asset. But...I think, for advanced learners, we have to allow English and other languages that they bring in classroom.

The above excerpt clearly imply that teachers' use of multilingual strategies helps in developing students' knowledge, understanding and for making them resourceful as an asset. The participants also claimed that only multilingual approach can bridge the knowledge gap. One of the participants claimed, 'multilingualism is inborn to us because our linguistic and social structure was never monolingual'. From the critical interpretation of the data, it has been concluded that the participants favored multilingual pedagogical strategies in teaching English. Their responses to the question for discussion show that multilingual pedagogy as a voice for language representation, justice and promotion.

Shifting towards Mono-to-Multilingual Pedagogy. The participants of the study equally presented themselves as well acquainted to the multilingual education and the importance of using languages as resource. The participants realized that multilingual awareness is increasing these days along with the voices raised by the experts, politicians and literacy educators. Since multilingualism has become a research backdrop (Kirkpatrick, 2016), the participants of the study felt the need of more discussion on the ways to make classroom multilingual. They insisted that education itself is not monolingual but it has been made like so. The growing awareness on the role of language transfer, teachers' self -practice, multilingual competencies, knowledge through languages and language for socio-economic and cultural capital have contributed to shift the language education from mono-to multi lingual practices in the view of my participants. Teacher-2, in this concern, argued:

We are becoming more aware on the importance of multilingual education and the experts have also raised their voices on it. And...the research literature is also growing on language issues. I think, it is partly true because we are interested on it. The need is to talk about the ways to make classroom multilingual. The awareness is increased and the research practice on it is also growing on.

Likewise, teacher-4 asserted:

Classroom teaching of English is becoming due to the growing awareness of the people. And it is the right time to talk about multilingual approach because the political system of nation is restructured and local units are given the rights to take decision about language. Multilingual practice is the need.

From the excerpts above, the researcher come to know that due to the growing awareness, need and interest of the people, political system of the nation, and the role of languages in knowledge transmission and substantial changes in learning, the language pedagogy has been shifted towards multilingual practices from the mono-lingual boundary. As Duff (2015) says the linguistic orientation of the world is crossing of cultural, ideological, linguistic, and geopolitical boarders and boundaries of all types, my participants also insisted to cross the mono linguistic and mono cultural boarders for shifting education system from mono- 
to-multilingual pedagogy.

Teachers as Multilingual Educators. Teachers have a big responsibility for bringing changes and reformation in the education system of a nation (Pennycook, 2001). Teachers should present themselves as the change agent of the society where they have been working (Cots, 2009) so as to noticeable changes. The teachers involved in interview and FGD presented themselves at least as the bilingual educators. They further claimed that they have motives to present themselves as the multilingual teachers in their actions. As the part of motives, they viewed that they are personally motivated to adopt multilingual educators. Those motives included: they try to give space to the students' first languages in class; they asked questions in students first language and encouraged to answer them in the language that they feel easier to express; they exposed with examples; they bridged the knowledge to each other through the interaction and realized the importance of language to construct new forms of understandings and identities; and helped students for text production and comprehension by providing meta-linguistic input in students' own languages. So far they asserted, the recent publications on multilingual education, media, and discourse on language issues inspired the participants to be multilingual teachers. They had never an experience of discriminating students in terms of language because they were guided by the spirit of linguistic equality and justice. In this regards, teacher-1 claimed:

I know the education system itself was not monolingual in the past but it was characterized in such a way, I don't fully agree on the statement that you said. Instead of being monolingual or bilingual, multilingual perspective is better. For knowledge transmission and bringing substantial changes, multilingual can be effective one. It is the thing that inspired me to be multilingual educator.

The participants further clarified that they used to contextualize the content with language and culture. For them, multilingual approach could address students' proficiency and right. Equally, they focused on language maintenance and shift to make learners more multilingual. As a part of evidence, teacher-3 argued:

As a teacher and a linguist, I can't be monolingual in my class because I have to address my students' proficiency and linguistic rights. I try to be in contact with students own languages. I have experienced both the shift and maintenance of language in our education system. Lets' see the communication style in new generations; they have used more mixed codes and moving towards the use of multiple languages.

From the statements and discussions above, it becomes clear that teachers had awareness on the need and importance of using multiple languages in the class. Their profession made them to be multilingual. They tried to be in contact with students own language and link up the implications of research on multilingual education in their classroom teaching. The heterogeneous class and bilingual students were also the motives for the teachers to present them in the form of multilingual educators.

Multilingual Strategies in Teachers' Experience. The experience of one teacher can be a source of inspiration to the others for adopting multilingual strategies (Okal, 2014). One of the objectives of this study was to explore the teachers' experiences on the use of multilingual strategies. So, during the interview and FGD, the participants were asked about their experience on practicing multilingual strategies. Synthesizing 
the views of the participants, the researcher identified the major approaches as: language associative techniques, e.g. linking up vocabulary meaning in students' languages; using translation as a technique to clarify the concept; providing exposure in multiple languages; bridging different cultural resource in class; integrate content and culture for explanation; respect students language in class; facilitate them to be bilingual through language transfer; making English as multi-lingual English through the feature of local accents; not being linguistically biased; encouraging students to contribute something in their own language; allow questions in students' own languages; and using as many languages as possible as the resource pool to impart information to the students. In this regards, the teacher-2 viewed:

I expose them to provide examples from their own language and link it up with the topic so far. I teach English with the examples of Nepali and other ethnic languages that I know. I allow them to use any language they like and later ask to translate in Nepali or English and say.

Likewise, Teacher-4 asserted:

I bridge different languages in the class and I provide exposure to the students. Throughout my practice of teaching, I made use of language to impart information not simply for taking, or showing myself as an expert speaker of a language. I used to integrate linguistic and cultural information in my classes. I encouraged them to speak in their first language.

With reference to the participants' experiences, I come to the conclusion that language associative techniques, translation, knowledge transfer, using as many languages as the resource pool, exemplification and meaning negotiation in students languages, making substantial use of Nepali language while teaching English and selecting different languages for reading and writing as the multilingual pedagogical approaches of the teachers.

\section{Alternative Strategies to Practice Multilingual Pedagogy in ESL/EFL Classes}

Among the participants, the most effective strategy to practice multilingual pedagogy in ESL/ EFL classes would be the teachers self practice of picking up as many languages as possible in class for content elaboration, contextualization, clarification and exposure. Besides this, they suggested many alternatives. Their views included: promoting students' first language by using them in classroom talk, casual talk and in writing; picking up the examples from different languages without taking language as a boundary because language is not an electric switch; teach, push and encourage reflecting in different languages; giving permission to ask and response in students' individual languages; providing exposure in English by bridging/blending local language input in the classes; and teaching by translating, paraphrasing, maintaining dependency in between languages, and establishing vocabulary relationships in many languages. Furthermore, they also argued to present content intelligible in many languages that the students possess; to take languages for learning base to the students; to motivate students to be multilingual by language transfer, translation, code switching and code messing; to make strategic plan for adopting multilingual approaches in action; to handle languages tactfully in class by bringing variety in learning tasks through the use of different languages; to explore and extend the functions of different languages and encouraging students to make use of those functions in their communication; and to be aware on 
the importance of individual languages, extending students' repertoire in different languages and using additive language instruction as the strategy. As the evidence, the teacher-5 suggested the alternatives as:

We have to encourage them to have a good English in writing and speaking but for knowledge and exposure, we need to provide them the information from multiple culture...we have to ask them to contribute something else in their language too. The more we try to use different languages, the more intelligible the content will be to the students. For example, we may paraphrase in different languages help them for getting the contents.

Supporting the same, teacher-4 argued:

We may ask students to promote their language by using it in classroom, in casual talk, in writing... and so on. Similarly, we can pick up the examples from two or more languages. We should think that all languages could be the best languages.

From the evidence above, it has also become clear that the teachers can play instrumental role to practice multilingual pedagogy in their classes with an attitude of using languages as a knowledge base, resource for developing competencies and tool for personal and professional growth (Strilling, 2001). The content for teaching should be selected from multiple linguistic and cultural sources. Resource management is important thing rather than language selection for effective MLE. It can be suggested that more discussion is essential and the local body should reformulate the policy and practice of language in classroom. Social realization is almost essential to promote languages through education.

\section{Teachers' Alternatives to the Policies for Multilingual Education}

It is said that the effective policy results better achievement in education system of a nation. There is a significant role of language policy to practice multilingual pedagogy in learning contexts. Language policy consists of three components: (i) language practices-actual use of language; (ii) language beliefs or ideology; and (iii) language intervention, planning or management (Spolsky, 2012). The teachers' conception of language policy allows the investigations of the actions of government and how such actions are interpreted and experienced by those they are designed to affect. Thus, at the final part of discussion, I interviewed the participants about their suggestions for implementing new policies in MLE. The most striking suggestions of them regarding the policy of multilingual education included: the language policy of the government should support the use of students' home language for their educational and cognitive development; the local people, local educational agencies, teachers and experts should be included in the policy making process, educational languages policies should be bottom-up; the 'one nation one language' policy disregarded the multilingual education in the past, so there must be pluralistic policy of language; multilingual input should be given through teacher education and training; multilingual pedagogy should be included in higher education curriculum, MLE should not be the political agenda rather, it should be the investment to enhance educational capabilities; the donor based policy should be demolished and research based implications should be the part of practice; and the agency based translation of textbooks from English and Nepali to ethnic/ indigenous languages should be avoided. In this regards, teacher-1 suggested as: 
... as a part of my suggestion, first there should be the efforts for teacher investment. Multilingual input should be invested in teacher education and in training. Second, the selection criteria should be made explicit. For example, selecting the teacher considering the linguistic structure of a community or the school looking at the majority of the students...our commitment works best as a policy. Another pity is that in our context, policy has never been a practice. The local body should be automatized. The consequences of monolingual policy should be examined and the practice of languages in pedagogy should be the part of discussion which has not been so.

From the overall discussion of the data and interview excerpt, it can be concluded that the language policy for practicing MLE should be explicit, workable, need based, research based, sensitive to the language structure and learning context of the classroom, visionary and realistic. The participants also suggested that the mother tongue based education policy for basic level and additive bilingual (Romaine, 2009) policy for higher level education is desirable. The policy should focus on resource developmentto-management-to-effective implementation stratagem. So, what is the need of present day pedagogy in Nepalese context is that the national policy of language teaching should use its own languages to enhance the multi-competence in the knowledge base of the students.

\section{Conclusion and Implications}

The results of the study depicted that the teachers favored multilingual pedagogical strategies in teaching English to the students from different linguistic and cultural backgrounds. Their innovative practices supported the use of students' home language for meaningful interaction and knowledge enrichment. As we have seen an extensive critiques have been mounted against the monolingual bias that pervades most areas of applied linguistics (Garcia, 2009; Edwards, 2010; \& Okal, 2014), the participants of this study attempted to shift their instructional strategies towards multilingual practices from the monolingual one.

As the study of Cenoz and Gorter, (2011) concluded that monolingualism is the default for human communication, the findings of this study too found in the same line. The participants of this study also perceived monolingual pedagogy as a barrier for students' knowledge base. The English language teachers asserted that due to the growing awareness on the use of language for linguistic and social capital of the students, the present day language pedagogy is steeping ahead towards multilingual education in both the pedagogical approaches and classroom practices of language. The results also depict that there is an increasing awareness in multilingual pedagogy. The English language teachers preferred multilingual pedagogical approaches for teaching content, developing knowledge and providing more social, linguistic and cultural capital of the students. Using multiple languages as a means to communicate content area, giving examples from different linguistic and cultural contexts, allow students to respond on their own language, bringing variety in tasks in different languages, and providing meta-linguistic input in students own language have been found as the strategies for making classroom more multilingual. These findings supported the ideas expressed by Okal (2014) in his study on the benefits of multilingualism in education. The participants argued that the policy should be based on classroom structure and language use to the students has been found as the suggestion to adopt multilingual policy in education. As a part of 
alternatives, it has been found that the teachers became realistic on linguistic structure and resources. They have invested language-culture connection approach in their pedagogy. So, the findings of the study have made call for a move from monolingual to a multilingual approach. Multilingual education is necessary for all children since it fosters multilingual and multicultural awareness, strengthens multilingual competence and enhances linguistic and cultural sensitivity. For collective disciplinary action to break away from the monolingual bias, viable alternatives must be offered to replace the prevalent monolingual theories, constructs and research practices. Thus, I would like to conclude with Cummins statement, "When we free ourselves from exclusive reliance on monolingual instructional approaches, a wide variety of opportunities arise for teaching languages"( 2007).

\section{References}

Awasthi, L. D. (2008). Importation of ideologies. From Macaulay minutes to wood commission. Journal of Education and Research,1 (1), 21-30.

Awasthi, L. D. (2011). The making of Nepal's language policy: Importation of ideologies. In L. Farrell, U. N. Singh, \& R. A. Giri (Eds.), English language education in South Asia: From policy to pedagogy (pp. 73-88). New Delhi, India: Cambridge University Press India.

Bloomaert, J. (2013). Policy, policing and the ecology of social norms: Ethnographic monitoring revisited. International Journal of Sociology of Language, 219, 123-140.

Cenoz, J. (2013). Multilingualism and Education. London: Sage.

Creswell, J. W. (2013). Qualitative inquiry and research design: Choosing among five approaches (3 ${ }^{\text {rd }}$ ed.). Thousand Oaks, CA: sage.

Cummins, J. (2007). Rethinking monolingual instructional strategies in multilingual classroom.Canadian Journal of Applied Linguistics, 10(2), 221-240.

Daniel, O., Orwego, M., Ruth, W., \& Nuding, W. (2014). Multilingualism and education in Africa: The state of the state of the Art. Journal of Educational Research 5(2), 253-269. doi: 1013189.

Deway, J. (1938). Experience and education. New York: Collier.

Duff, P. A. (2015).Transnatinalism, multilingualism, and identity.Annual Review of Applied Linguistics, $35(10), 57-80$.

Edwards, J. (2010). Language diversity in the classroom. London: Academic Press.

Garcia, O. \& Kleifgen, J. (2010) Educating Emergent Bilinguals: Policies, Programs and Practices for English Language, New York; Teachers College Press.

Garcia, O. \& Sylvan, C. (2011) "Pedagogies and Practices in Multilingual Classrooms: Singularities in Pluralities," Modern Language Journal 95(3), 385-400.

Gee, M. (2005). Language, Ethnicity and cultural change.London: Routledge.

Giri, R. A. (2011). Languages and language politics: How invisible language politics produces visible results in Nepal. Language Problems \& Language Planning. 16 (1), 32-44.

Garcia, O. (2009). Translanguaging: Language, education, and bilingualism. New York: Palgrave Macmillan.

Garcia, O. (2016). Routledge companion to English studies. London: Routledge. 
Jessner, U. (2008). Multicompetence approaches to language proficiency development in multilingual education. In J. Cummins \& C. Davies (Eds.), The handbook of English language teaching. Dordrecht: Springer.

Kincheloe, J. L. \& McLaren, P. (2000).Rethinking critical theory and qualitative research.In N.K. Denzin \& Y. S. Lincoln (Eds.), Handbook of qualitative research ( $2^{\text {nd }}$ ed., pp. 279-313). Thousand Oaks, CA: Sage.

Kirkpatrick, R. (2016). English language education policy in Asia. Switzerland: Springer International Publishing.

Koirala, B.N. (2016). Multilingual language policies in education: Critical issues. In Contributions to Nepalese Studies. Kathmandu: CNAS, Tribhuvan University 22, 73-86.

Morse, J. M. (2001). Determining sample size.Qualitative Health Research, 10, 3-5.

Mutiga, J. (2005). The impact of a national language on other indigenous languages: The case of Kenya. In Proceedings of 17th-18th March on Across Borders: Benefiting from cultural differences, DAAD Regional Office in Africa.

Pennycook, A. (2001). Critical applied linguistics: A critical introduction. New Jersey: Lawerence Erlbaum Associates.

Okal, B. D. (2014).Benefits of Multilingualism in Education.Universal journal of Educational Research 2 (3), 223-229, DOI: 1013189.

Philipson, R. (1997). Realities and myths of linguistic imperialism.Journal of Multilingual and Multicultural Development, 18 (3), 238-248.

Phyak, P. (2013). Language ideologies and local languages as the medium of instruction policy: A critical ethnography of a multilingual school in Nepal. Current Issues in Language Planning, 14 (1), 127 143.

Phyak, P. (2016). Local-global tension in the ideological construction of English language education policy in Nepal. In R. Kirkpatrick (Ed.), English language education policy in Asia. Switzerland: Springer International Publishing.

Piller, I. (2016). Monolingual ways of seeing multilingualism. Journal of multicultural discourses, 11 (1) 25-33.

Powell, R. A. \& Single, H. M. (1996).Focus groups. International Journal of Quality in Health Care, 8 (5), 499-504.

Rai, V. S., Rai, M., Phyak, P., \& Rai, N. (2011). Multilingual education in Nepal: Hearsay and reality. Kathmandu, Nepal: UNESCO.

Romaine, T. (2009). Imperial language policy and political Economy. Oxford, New York: Oxford University Press.

SDC. (2016). A report on languages used in the classroom interaction in national schooling system. Ministry of Education: Kathmandu.

Spolsky, B. (2012). What is language policy? In B. Spolsky (Ed.), The Cambridge handbook of language policy (pp. 3-15). Cambridge, UK: Cambridge University Press. 
Starks, H. \& Trinidad, S. B. (2007). Choose your method: A comparison of phenomenology, discourse analysis and grounded theory. Qualitative Health Research, 17, 1372-1380.

Strilling, J. A. (2001). Thematic networks: an analytic tool for qualitative research. Qualitative Research, $1(3), 385-405$.

Taylor, P. C. \& Medina, M. N. (2013). Educational research paradigms: From positivism to multiparadigmatic. The Journal of Meaning-Centered Education. 1 (2).

Willis, J. W. (2007). Foundations of qualitative research: Interpretive and critical approaches. Thousand Oaks, CA: Sage.

\section{APPENDIX A}

\section{Interview Questionnaire}

1. The pedagogy of language has become more multilingual at present. How do you agree on it?

2. Would you like to present yourself as a multilingual academician? How do you do so?

3. Would you mind sharing me your experiences of adopting multilingual pedagogical approaches in your classroom instruction?

4. In your own experience and understanding, what makes a classroom really multilingual?

5. Would you like to suggest any specific ways to make our L2 classes more multilingual?

6. What should be the educational policy for applying multilingual pedagogy in our like heterogeneous classes?

7. As a teacher of English, what do you think about the position of English and other indigenous languages in English classroom?

8. What sorts of attempts have you made so far to make your class more multilingual and language inclusive

\section{Appendix B}

\section{FGD Guidelines}

Discussion on: Multiligualism and language education

: Multilingual education and medium of instruction

: Multilingual pedagogy

: Ways to make classroom really multilingual

: Multilingual classroom policies and practices

: Strategies to be more multilingual in action not in words

Mr. Guru Poudel has been teaching to the M.Ed. students in the Department of English Education, T.U and Kathmandu Shiksha Campus, Kathmandu for the last seven years. Currently, he has been contributing as an executive member of NELTA and has also been pursuing M. Phil in English language education from T.U. 